\title{
Carcinoma de tireóide em crianças e adolescentes - revisão de seis casos
}

\author{
Thyroid carcinoma in children and adolescents - review of six cases \\ Daniela V. M. Szeliga ${ }^{1}$, Nuvarte Setian ${ }^{2}$, Leonardo D. Passos ${ }^{3}$, Thais M. R. Lima ${ }^{4}$, \\ Thais Della Manna $^{5}$, Hilton Kuperman ${ }^{6}$, Durval Damiani ${ }^{7}$, Vaê Dichtchekenian ${ }^{8}$
}

\section{Resumo}

Objetivo: O carcinoma de tireóide é raro em crianças, e existem aspectos controversos sobre seu manejo. Este estudo foi realizado para avaliar aspectos diagnósticos e de seguimento destes pacientes.

Métodos: Foi revisada retrospectivamente a evolução clínica de seis pacientes com carcinoma de tireóide, seguidos em Unidade de Endocrinologia Pediátrica nos últimos 17 anos.

Resultados: Foram encontrados seis pacientes com carcinoma de tireóide, todos do sexo feminino, com idade de 4,5 a 12 anos. Nódulo tireoidiano esteve presente na avaliação inicial em todos os casos. A ultra-sonografia e cintilografia com ${ }^{131}$ I mostraram nódulo sólido e hipocaptante em quatro pacientes. Histologicamente, quatro eram carcinomas papilíferos, e dois foliculares. Todos foram submetidos à tireoidectomia total, sendo que quatro necessitaram também dose terapêutica de ${ }^{131}$ I devido a metástases e/ou resíduo tireoidiano.

Conclusão: Nossos achados confirmaram a impressão clínica de que crianças e adolescentes com carcinoma tireoidiano têm um bom prognóstico, sem haver registro de óbito neste seguimento de até 17 anos. Estes dados estão de acordo com a literatura, que mostra baixa mortalidade nestes casos.

J Pediatr (Rio J) 2001; 77(1):45-48: tireóide, carcinoma de tireóide, nódulo tireoidiano, crianças e adolescentes.

\section{Introdução}

O carcinoma de tiróide é uma entidade rara nas primeiras duas décadas de vida. Estima-se que apenas 10\% do total destes carcinomas ocorra nesta faixa etária ${ }^{1}$. Na popu-

1. Pediatra pós-graduanda em Endocrinologia Pediátrica.

2. Professor Associado de Pediatria Clínica e Chefe da Unidade de Endocrinologia Pediátrica.

3. Pediatra pós-graduando em Endocrinologia Pediátrica.

4. Pediatra pós-graduanda em Endocrinologia Pediátrica.

5. Mestre e Médica Assistente, Endocrinologia Pediátrica.

6. Mestre e Médico Assistente, Endocrinologia Pediátrica.

7. Assistente Doutor, Endocrinologia Pediátrica.

8. Assistente Doutor, Endocrinologia Pediátrica.

\begin{abstract}
Objective: Thyroid carcinoma occurs rarely in children, and there are controversial aspects about its management. This study was carried out to evaluate diagnostic and follow-up aspects of these patients.

Methods: The clinical courses of six patients with thyroid cancer followed in a Pediatric Endocrinology Unit for 17 years were retrospectively reviewed.

Results: There were six females ranging in age from 4.5 to 12 years. At initial examination thyroid nodules were present in all cases. The ultrasonography and ${ }^{131}$ I scan showed solid and cold nodules in four patients. Histologically, four were papillary and two were follicular carcinomas. All of them underwent total thyroidectomy, four also had to do radioiodine therapy because of the presence of metastasis and/or thyroid remnants.

Conclusions: Our findings support the clinical impression that children and adolescents with thyroid carcinoma have a good prognosis: there were no deaths in this follow-up of 17 years. These data are similar to those in the literature, that reveals low mortality in these cases.
\end{abstract}

JPediatr (Rio J) 2001; 77(1):45-48: thyroid, thyroid carcinoma, thyroid nodule, children and adolescents.

lação geral, sua ocorrência é de um caso novo por milhão de pessoas por ano ${ }^{2}$, com pico de incidência entre os 10 e os 20 anos $^{3}$, correspondendo a $0,5-3 \%$ das doenças malignas em crianças e adolescentes ${ }^{1}$. Afeta mais meninas que meninos, numa proporção de 2-2,5:1,4. Em áreas com fatores de risco, como na República de Belarus, devido ao acidente atômico de Chernobyl, a ocorrência pode alcançar até 80100 por milhão por ano ${ }^{2}$.

O tipo histológico mais comum é o carcinoma papilífero, sendo o folicular menos comum, e o medular e o anaplásico muito raros. A etiologia é desconhecida, mas existem fatores de risco específicos que aumentam a inci- 
dência, incluindo exposição a radiação, deficiência de iodo, tireoidite de Hashimoto prévia, outras condições associadas com prolongada elevação de TSH sérico ${ }^{3}$ e fatores genéticos que estão presentes tanto por mutação espontânea quanto por herança direta, como ocorre no carcinoma medular de tireóide. Estudos mostram que 50\% dos carcinomas tireoidianos apresentam tireoidite concomitante ${ }^{5}$.

A influência da exposição à radiação tem sido estudada há cinco décadas, tendo sido inicialmente sugerida por Duffy e Fitzgerald em $1950^{4}$. A irradiação externa resultante de exposição à bomba atômica e irradiação terapêutica de cabeça e pescoço em crianças estão associadas com o desenvolvimento de neoplasia tireoidiana, em dez ou mais anos após a exposição. Sabe-se que a irradiação com Iodo $131\left({ }^{131} \mathrm{I}\right)$ para tratamento de Doença de Graves não é carcinogênica para a tireóide adulta; no entanto, essa conclusão não pode ser extrapolada para crianças e adolescentes, devido à experiência muito limitada ${ }^{2}$.

Entre 1951 e 1970 houve grande aumento na prevalência de carcinoma papilífero e folicular em crianças e adolescentes, provavelmente pela introdução, em 1940, de irradiação de cabeça e pescoço para tratamento de condições benignas como aumento de timo, hiperplasia adenoamigdaliana e linfadenopatia cervical ${ }^{4}$.

O objetivo deste estudo é avaliar os casos de carcinoma tireoidiano em seguimento em nosso serviço, discutindo aspectos diagnósticos e terapêuticos e o grau de malignidade com seu conseqüente risco de vida.

\section{Métodos}

Foram avaliados em estudo retrospectivo dos últimos 17 anos, dentre os 354 pacientes com doença tireoidiana em seguimento na Unidade de Endocrinologia Pediátrica do Instituto da Criança do HC-FMUSP, seis pacientes com carcinoma tireoidiano, todos do sexo feminino e com idades variando de 4,5 a 12 anos. A avaliação foi feita com dados clínicos e laboratoriais através de dados de hormônio tireoidiano (T3, T4, T4 livre), TSH, tireoglobulina, anticorpos anti-tireoperoxidase (antiTPO) e antitireoglobulina (antiTG), dosados por método de radioimunoensaio e/ou imunofluorescência, teste do perclorato, ultra-sonografia tireoidiana, cintilografia tireoidiana e de corpo inteiro com ${ }^{131}$ I e análise cito e histológica de material obtido por punção aspirativa com agulha fina (PAAF) e biópsia excisional, respectivamente.

\section{Resultados}

Dos 354 pacientes com tireoidopatia em seguimento na Unidade de Endocrinologia Pediátrica do ICr HC-FMUSP nos últimos 17 anos, seis apresentavam carcinoma tireoidiano, correspondendo a $1,7 \%$ do total e a $2,7 \%$ dos casos de bócio (total=217 casos).
Os seis pacientes com carcinoma tireoidiano eram do sexo feminino, com idade variando de 4,5 a 12 anos e procuraram o serviço devido à presença de nódulo tireoidiano. A história familiar e de irradiação de cabeça e pescoço foi negativa em todos os casos. Não se registrou presença de linfonodomegalia regional, aderência a tecidos adjacentes ou voz grossa e rouca que pudesse sugerir neoplasia tireoidiana. Quanto à função tireoidiana, cinco pacientes apresentavam-se eutireóideas e uma hipotireóidea, com anticorpos (antiTPO e antiTG) negativos. A tireoglobulina foi dosada em duas pacientes no pré-operatório, estando acima dos valores de referência em uma delas. No pós-operatório a tireoglobulina esteve elevada em duas pacientes. $O$ teste do perclorato foi positivo em um caso. Ultra-sonografia e cintilografia pré-operatórias foram realizadas em quatro pacientes, mostrando em todas nódulo sólido e hipocaptante (frio), respectivamente. Duas pacientes foram submetidas a PAAF para diagnóstico citológico, e as outras quatro foram submetidas a biópsia excisional. Cito e/ou histologicamente, quatro pacientes apresentavam carcinoma papilífero, e duas, carcinoma folicular, sem tireoidite concomitante. Todas foram submetidas a tireoidectomia total. Cintilografia de corpo inteiro foi realizada em todas as pacientes no pós-operatório, mostrando captação em quatro pacientes. Quatro pacientes apresentaram resíduo tireoidiano, e uma destas, também metástase pulmonar, diagnosticados por cintilografia de corpo inteiro e/ou dosagem de tireoglobulina. Todas estas foram submetidas a dose terapêutica de iodo radioativo.

\section{Discussão}

A queixa principal em todas as pacientes deste grupo foi a presença de nódulo tireoidiano assintomático; a literatura registra esta apresentação como clínica inicial em 60-80\% dos casos de carcinoma de tireóide ${ }^{3}$. História de exposição prévia a radiação ambiental ou terapêutica é importante, apesar de nenhuma destas pacientes terem este dado positivo.

Cinco pacientes apresentavam-se eutireóideas ao diagnóstico, uma apresentava-se com hipotireoidismo por deficiência de síntese hormonal e, conseqüentemente, com TSH elevado, o que é considerado fator de risco para carcinoma tireoidiano, conforme já mencionado. Todas as pacientes apresentaram anticorpos (antiTPO e antiTG) negativos; no entanto, a literatura cita que estes estão aumentados numa frequiência três vezes maior em pacientes com carcinoma tireoidiano do que na população em geral, $40 \%$ e $14 \%$, respectivamente ${ }^{6}$. A avaliação de tireoglobulina sérica é útil no seguimento destes pacientes, podendo alertar para uma possível recorrência da doença; neste estudo, esteve elevada em duas das quatro pacientes que apresentavam metástases e/ou resíduo tireoidiano. 
Quatro pacientes foram submetidas a ultra-sonografia e cintilografia pré-operatória, mostrando em todos os casos, nódulo sólido e hipocaptante; nestes casos, a literatura cita presença de malignidade em $17-36 \%$. Devido à grande frequiência de carcinoma em crianças e adolescentes com nódulo tireoidiano, a biópsia excisional é preferida à punção aspirativa com agulha fina (PAAF), em contraste com adultos. No entanto, estudos recentes têm mostrado que em mãos experientes, a PAAF pode ser útil no manejo de nódulos tireoidianos em crianças ${ }^{7}$. Das seis pacientes, duas foram submetidas a punção aspirativa do nódulo, com laudo citológico compatível com o anátomo-patológico pós-operatório de carcinoma papilífero. As outras foram submetidas a biópsia excisional. A histologia mostrou um total de quatro carcinomas papilíferos e dois carcinomas foliculares; esta maior incidência de carcinoma papilífero também é registrada por outros autores ${ }^{1-4,7-9}$.

A tireoidectomia total é o procedimento de escolha para tumores malignos de tireóide, apesar da alta taxa de lesão de nervo laríngeo recorrente e do hipoparatireoidismo, este último sendo encontrado em 7 a $27 \%$ dos $\operatorname{casos}^{8}$. Em pacientes com carcinoma papilífero, sem invasão tumoral, metástases ou história de exposição a radiação nas primeiras 3 décadas de vida, alguns cirurgiões preferem excisão do lobo afetado, istmo e linfonodos adjacentes. Este procedimento é sustentado devido à baixa mortalidade por carcinoma papilífero após 40 anos de diagnóstico, e também pelo fato de que a terapia supressiva do TSH com tiroxina tem efeito supressor nestes tumores ${ }^{2}$. Defensores da tireoidectomia total justificam este procedimento com a alta incidência de doença multifocal, sendo encontrado em $40 \%$ dos $\operatorname{casos}^{8}$. Estudos mostram melhor evolução após ressecção completa e em pacientes mais velhos ${ }^{9}$, havendo até $60 \%$ de recidiva em menores de 7 anos, contra $27 \%$ em maiores ${ }^{8}$. As seis pacientes estudadas foram submetidas a tireoidectomia total, sem nenhuma complicação pós-operatória, seguida de reposição hormonal com tiroxina para manter TSH entre 0,05 e $0,1 \mathrm{mcU} / \mathrm{ml}$. Estudos mostram recidivas mais freqüentes em pacientes que não usaram esta terapia supressiva do $\mathrm{TSH}^{8}$.

No pós-operatório (até três meses), foram dosados os níveis séricos de tireoglobulina como marcador tumoral e realizada cintilografia de corpo inteiro, sendo encontrados quatro pacientes com tireóide residual e uma destas apresentou, além da tireóide residual, metástase pulmonar, presente em 10-20\% dos carcinomas tireoidianos em crianças ${ }^{1}$. Nenhum paciente apresentou metástase para linfonodos regionais, apesar de na literatura ser encontrado em 80$90 \%$ dos $\operatorname{casos}^{1,3}$. Apesar de ser o carcinoma folicular biologicamente mais agressivo que o carcinoma papilífero, os dois casos com carcinoma folicular não apresentaram metástases, estando um deles com 16,2 anos de seguimento.

Todos os quatro casos com resíduo tireoidiano e metástase foram tratados com dose terapêutica de ${ }^{131} \mathrm{I}$, com ablação do tecido residual. Um dos casos apresentou persis- tência da captação pulmonar, no entanto, tem se mantido estável, recebendo dose adequada de tiroxina para supressão do TSH. As duas pacientes que não apresentaram resíduo tireoidiano ou metástases, não receberam ${ }^{131} \mathrm{I}$, conduta adotada também por outros autores, apesar de ser controversa $^{12}$.

Alguns autores encontraram evidências de fibrose pulmonar com restrição pulmonar moderada a grave em 4 de 10 pacientes avaliados com prova de função pulmonar após dose terapêutica de radioiodo ${ }^{5}$. A paciente com metástase pulmonar avaliada neste estudo não apresentou sintomas sugestivos de fibrose pulmonar.

Nossa casuística, com seguimento de até 17 anos, constatou o bom prognóstico do carcinoma tireoidiano, sem registro de óbito, o que está de acordo com dados da literatura, que cita baixa taxa de mortalidade ${ }^{1-4,8-11}$. Todas as pacientes estão bem controladas, cinco delas sem sinais de doença ativa e uma com metástase pulmonar estável, como descrito acima.

\section{Referências bibliográficas}

1. Millman B, Pelliteri PK. Thyroid Carcinoma in Children and Adolescents. Arch Otolaryngol Head Neck Surg 1995; 121:1261-64.

2. Foley Jr TP. Disorders of the Thyroid in Children. In: Pediatric Endocrinology. $1^{\text {st }}$ ed. Philadelphia: Saunders Company; 1996. p.171-94.

3. Feinmesser R, Lubin E, Segal K, Noyek A. Carcinoma of the Thyroid in Children - A Review. Jounal of Pediatric Endocrinology \& Metabolism 1997;10:561-68.

4. Foley T, Malvaulx P, Blizzard R. Thyroid Disease. In: The Diagnosis and Treatment of Endocrine Disorders in Childhood and Adolescence. $4^{\text {th }}$ ed. Springfield-Illinois-USA: Charles C. Thomas Publisher; p. 457-533.

5. Flannery TK, Kirkland JL, Copeland KC, Bertuch AA, Karaviti LP, Brandt ML. Papillary Thyroid Cancer: a Pediatric Perspective. Pediatrics 1996;98:464-66.

6. Spencer CA, Takeuchi M, Kazarosyan M, Wang CC, Guttler RB, Singer PA, et al. Serum thyroglobulin autoantibodies: Prevalence, influence on serum thyroglobulin measurement, and prognostic significance in patients with differentiated thyroid carcinoma. Journal of Clinical Endocrinology and Metabolism 1998;83:1121-27.

7. Raab SS, Silverman JF, Elsheikh TM, Thomas PA, Wakely PE. Pediatric thyroid nodules: Disease dermographics and clinical management as determined by fine needle aspiration biopsy. Pediatrics 1995;95:46-9.

8. Massimo M, Gasparini M, Ballerini E, Del Bo R. Primary Thyroid Carcinoma in Children: A Retrospective Study of 20 Patients. Medical and Pediatric Oncology 1995;24:13-7.

9. Newman KD, Black T, Heller G, Azizkhan RG, Holcomb GW, Sklar C, et al. Differentiated thyroid cancer: Determinants of disease progression in patients $<21$ years of age at diagnosis. Annals of Surgery 1998;227:533-41.

10. Samuel AM, Rajashekharrao B, Shah DH. Pulmonary metastases in children and adolescents with well differentiated thyroid cancer. Jounal Nucl Med 1997;39:1531-36. 
11. Vassinopoulou-Sellin R, Goepfert H, Raney B, Schultz PN. Differentiated thyroid cancer in children and adolescents: Clinical outcome and mortality after long-term follow-up. Head \& Neck 1998;20:549-55.

12. Wartofsky L, Sherman SI, Gopal J, Schlumberger M, Hay ID. Therapeutic controversy - The use of radioactive iodine in patients with papillary and follicular thyroid cancer. Journal of Clinical Endocrinology and Metabolism 1998;83:4195-203.
Endereço para correspondência:

Dr. Nuvarte Setian

Rua Voluntários da Pátria, 3812

São Paulo - SP

Fone: 116977.0940 